\title{
SYNERGY OF SECONDARY COMPOUNDS IN THE ARTIFICIAL FOODS OF THE LAST INSTAR OF HYPHANTRIA CUNEA (DRURY) (LEPIDOPTERA: ARCTIIDAE)
}

\author{
YANAR, O. ${ }^{1 *}-$ TOPKARA, E. F. ${ }^{1}-$ GÖMEÇ, S. ${ }^{1}$ \\ ${ }^{1}$ Ondokuz Mayls University, Faculty of Arts and Sciences, Department of Biology, 55139 \\ Samsun, Turkey \\ (phone: +90-362-3121919/5585; fax: +90-362-4576081) \\ *Corresponding author \\ e-mail: oyanar46@gmail.com \\ (Received $1^{\text {st }}$ Dec 2015; accepted 26 ${ }^{\text {th }}$ Apr 2016)
}

\begin{abstract}
This study aims at putting forward the synergy of secondary compounds on total food consumption, the amount of pupal lipid and protein, weight of pupae, and development time in the last instar of Hyphantria cunea. A non-choice feeding experiment was applied with a total of 14 foods; one of them was the control food, 9 of them were prepared by adding different concentrations of tannic acid, gallic acid and $p$-coumaric acid (1, 3, 5\% of dry weight) to the control food, 3 foods with 2 combinations prepared by adding $3 \%$ concentration tannic acid, gallic acid and $p$-coumaric acid, and 1 food with three combinations. The total food consumption of the foods with double combinations was different when compared to control food. The pupal weights of the larvae which were fed with food containing two combinations (tannic acid+ $p$-coumaric acid) and the ones fed with food containing three combinations (tannic acid + gallic acid $+p$-coumaric acid) were different from the ones in the control group. The pupal protein content in food containing triple combinations was lower than the control food. The pupal lipid content in food containing triple combinations was more than the control food. It was found that the development time increased as the tannic acid concentration of the food increased; on the contrary, the development time decreased as the gallic acid concentration of the food containing gallic acid increased.

Keywords: Hyphantria cunea, secondary compounds, tannic acid, gallic acid, p-coumaric acid
\end{abstract}

\section{Introduction}

Secondary plant compounds serve different ecological functions such as allelopathy, herbivore deterrence, attraction of pollinators, predation of organisms on herbivores, and antifungal effect (Chou and Kuo, 1986; Harborne, 1977; Baas, 1989; Dicke and Sabelis, 1989). Through the observations deduced from the feeding behaviours of herbivore insects, it is known that these compounds perform the function of being deterrent to the herbivores or being toxic against them (Fraenkel, 1959; Ehrlich and Raven, 1964).

Phenolic compounds, which are a group of secondary compounds, are aromatic compounds containing one or more hydroxyl groups. There are more than 8000 known phenolic compounds in nature and 14 groups are categorized depending on the arrangements of these compounds; a small group of these compounds functions in plant-herbivore interactions (Strack, 1997). The physiological roles of phenolic compounds vary depending on their chemical structure and physicochemical environment (such as PH, redox potential, oxidase concentration, oxidants and antioxidants) (Larson, 1995; Metadiewa et al., 1999; Sugihara et al., 1999; Galati et al., 2002; Sakihama et al., 2002; Hagerman et al., 2003). 
Tannins which are accumulated against herbivorous animals in many plant species and especially in trees (Bernays et al., 1989; Peters and Constabel, 2002) show their biological effects through protein binding. It is shown that they have affected a great number of herbivores ranging from insects to mammals (Bernays et al., 1989). Gallic acid is a phenolic whose molecular weight is small. Gallic acid is derived from chrosmic acid by means of shikimic acid. It is known that gallic acid has antioxidant, antibacterial, anti-inflammatory and chemical protective properties (Kang et al., 2008; Kim et al., 2006; Giftson et al., 2009). p-Coumaric acid is an intermediate in biosynthesis of lignin and has a broad distribution in angiosperm plants (Berenbaum, 1982). $p$-Coumaric acid is of great importance because of its protective chemical and antioxidant properties (Torres and Rosazza, 2001).

This research aims at studying the synergistic effect of secondary compounds on $H$. cunea. For this purpose, 3 phenolic compounds (tannic acid, gallic acid and $p$-coumaric acid) with different molecular weights have been used and the synergistic effect of these phenolics on the nutrition and growth of the last instar has been studied.

\section{Materials and methods}

\section{Collection of the larvae}

H. cunea larvae were collected during the field research from hazelnut gardens on the coast within the Çarşamba border in Samsun in July, 2011.

\section{Feeding experiment}

10 different data were collected from the last instar larvae with an aim to be associated with a number of earlier publications in literature (Telang et al., 2001; Lee et al., 2002; Henriksson et al., 2003; Lee et al., 2004). For each food group, 10 larvae were put in plastic cases (sized $5 \mathrm{~cm} \times 10 \mathrm{~cm} \times 2 \mathrm{~cm}$ ) one by one. The larvae in the cases were put in an incubator adjusted to $27{ }^{\circ} \mathrm{C}$ heat and $70 \%$ humidity within a period of $16 \mathrm{~h}$ light $8 \mathrm{~h}$ dark. Each molting was noted and the data obtained from the last instar to pupae were evaluated. In feeding experiments, each day after weighed in 0,001 gr sensitive scale a new food, it was given and after the remaining food was dried in the incubator, and their dry weight was calculated. Moreover, each day the changes in the weight and their feces were noted and these measurements were followed until the larvae became pupae.

\section{Secondary compounds}

The first factor in choosing the secondary compounds is whether these compounds react with each other when they are included within food in double and triple combinations. As three of the secondary compounds have an acidic property- though the reaction was a weak possibility- tannic acid, gallic acid and $p$-coumaric acid were mixed in double and triple combinations in aqueous media at room temperature with a proportion of 1:1. However, no chemical reaction or change was observed. The other reason for choosing these 3 secondary compounds (tannic acid $\left(\mathrm{C}_{76} \mathrm{H}_{52} \mathrm{O}_{46}\right)$, gallic acid $\left(\mathrm{C}_{7} \mathrm{H}_{6} \mathrm{O}_{5}\right)$, p-coumaric acid $\left.\left(\mathrm{C}_{9} \mathrm{H}_{8} \mathrm{O}_{3}\right)\right)$ is that they have different molecular weights. 


\section{Content of artificial foods}

In this research, artificial foods with different contents were prepared with the aim of determining the effects of different secondary compounds and their different combinations on the nutrition and the growth of H. cunea. The artificial food which was developed by Yamamoto (1969) to feed the larvae was modified (only the protein and carbohydrate amounts were changed) and used as the control food and foods were prepared by using the secondary compounds such as tannic acid (TA) (Sigma, 16201), gallic acid (GA) (Sigma, G 7384) and p-coumaric acid (PCA) (Sigma, C 9008) suitable for the purpose of this research. By adding an amount of 1,3 and 5\% of tannic acid, gallic acid and p-coumaric acid of total dry weight to artificial food, 9 foods were prepared and by adding an amount of $3 \%$ of tannic acid, gallic acid and $p$-coumaric acid of dry weight to artificial food, 3 foods with double combination, a food with triple combination (TA+GA+PCA) and a control food were prepared. Therefore, 14 foods were prepared. These foods are shown in Table 1.

Table 1. Food types and contents

\begin{tabular}{|c|c|}
\hline Food types & Food contents \\
\hline $\mathrm{A}$ & Control Food $(\mathrm{CF})$ \\
\hline $\mathrm{B}$ & $\mathrm{CF}+\% 1 \mathrm{~T} . \mathrm{A}$. \\
\hline $\mathrm{C}$ & $\mathrm{CF}+\% 3 \mathrm{~T} . \mathrm{A}$. \\
\hline $\mathrm{D}$ & $\mathrm{CF}+\% 5 \mathrm{~T} . \mathrm{A}$. \\
\hline $\mathrm{C}$ & $\mathrm{CF}+\% 1 \mathrm{G} . \mathrm{A}$. \\
\hline $\mathrm{G}$ & $\mathrm{CF}+\% 3$ G.A. \\
\hline $\mathrm{H}$ & $\mathrm{CF}+\% 5$ G.A. \\
\hline $\mathrm{C}$ & $\mathrm{CF}+\% 1$ P.C.A. \\
\hline $\mathrm{CF}+\% 3$ P.C.A. \\
\hline $\mathrm{M}$ & $\mathrm{CF}+\% 5$ P.C.A. \\
\hline $\mathrm{N}$ & $\mathrm{CF}+\% 3 \mathrm{~T} . \mathrm{A} .+\% 3$ G.A. \\
\hline $\mathrm{P}$ & $\mathrm{CF}+\% 3 \mathrm{~T} . \mathrm{A} .+\% 3$ P.C.A. \\
\hline $\mathrm{CF}+\% 3$ G.A. $+\% 3$ P.C.A. \\
\hline
\end{tabular}

The content of Yamamoto's artificial food is wheat germ (Sigma, W-0125), casein as the protein (Sigma, C 6554), (30g/kg (modified amount)); saccharose as the carbohydrate (Sigma, S 1888), (30g/kg (modified amount)), torula yeast (Sigma, Y 4625), vitamin mixture (Sigma, V-1007), salt mixture (Sigma, W 1374), cholesterol (Sigma, C 2044), sorbic acid (Sigma, S 1626), methyl paraben (Sigma, H 3647), linseed oil (Sigma, L 3026), agar and water.

\section{Statistical analyses}

In this research, whether there was a difference between the data of total food consumption, pupal weight, the amount of pupal lipid and protein, and the development time was determined by ANOVA (Dunnet test). For these tests, SPSS 17 version from a minicomputer was used. 


\section{Results}

In accordance with the feeding experiment carried out on $H$. cunea larvae and with 14 artificial foods, 13 of these were prepared by adding secondary compounds at different rates and 1 as control group, the consumption amount of larvae, protein and lipid amounts of pupae, pupal weight and development time were explained under each heading. The data obtained from the Dunnet test is shown in Table 2.

\section{Total food consumption}

When compared to control food, total food consumption was statistically different in larvae that were fed in the other food groups. Compared with the control group, when 3 different concentrations of tannic acid, gallic acid and $p$-coumaric acid were considered, it is certain that there was a difference in the effect of 3 secondary compounds on the total food consumption. It was found that in comparison to the control group, as the secondary compound concentration increased in the food containing both tannic and $p$ coumaric acid (except for $\mathrm{H}$ food), there was a decrease in the total food consumption. On the contrary, as the secondary compound concentrations increased in food containing gallic acid, the total food consumption also increased.

The lowest total food consumption was found in the larvae fed by food containing $5 \%$ of tannic acid. When compared to the control group, the groups that had the maximum total food consumption contained food that had 1, 3 and $5 \%$ gallic acid. The total food consumptions of the larvae fed on double (M, N, P foods) and triple (R food) combinations were different when compared to control food (A). The total food consumption in $\mathrm{M}$ food was much more than the control food. However, the total food consumption in $\mathrm{N}$ food was less than that of the control group. The total food consumption in the larvae that were fed with $\mathrm{P}$ food increased when compared to control group. Moreover, it should be pointed out that there was no statistically, significant difference between the larvae feeding on $\mathrm{R}$ food and the control food.

\section{Pupal weight}

The pupal weight of the larvae feeding on the food containing 1, 3 and 5\% concentration of TA and GA and on the food containing 5\% of PCA were statistically different from the control group. In comparison to the control food, when tannic acid (except for 3\% of TA) and p-coumaric acid concentrations in foods increased, the pupal weight decreased. On the contrary, when the gallic acid concentrations increased, the pupal weight also increased.

The lowest pupal weight was found in the larvae feeding on $\mathrm{N}$ food. The highest pupal weight was obtained from the larvae feeding on $\mathrm{G}$ food. $\mathrm{N}$ food among the food containing double combinations and the $\mathrm{R}$ food containing triple combinations were statistically different from those in the control food. The pupal weight of the larvae feeding on $\mathrm{N}$ food among the double combinations was lower than larvae feeding on control food. Similarly, the pupal weight of the larvae feeding on R food was lower than those in the control food.

\section{Pupal protein content}

There was no statistical difference between the control food and the pupal protein content of the larvae feeding on $\mathrm{H}$ and $\mathrm{P}$ foods. When the secondary compounds which 
were added to the foods containing both tannic and $p$-coumaric acid increased, the pupal weight decreased. On the contrary, when the gallic acid concentration increased, the pupal weight also increased.

Table 2. The development time, total food consumption, pupal weight, the amount of pupal protein and lipid of H.cunea in the no-choice feeding experiment.

\begin{tabular}{|c|c|c|c|c|c|c|}
\hline & $\begin{array}{l}\text { Food } \\
\text { types }\end{array}$ & $\begin{array}{l}\text { Total food } \\
\text { consumption } \\
\text { (mg) }\end{array}$ & $\begin{array}{l}\text { Pupal weight } \\
\text { (mg) }\end{array}$ & $\begin{array}{l}\text { Amount of pupal } \\
\text { protein } \\
(\mathrm{mg})\end{array}$ & $\begin{array}{c}\text { Amount of pupal } \\
\text { lipid } \\
\text { (mg) }\end{array}$ & $\begin{array}{l}\text { Development time } \\
\text { (day) }\end{array}$ \\
\hline & A & $223,8 \pm 2,4$ & $25,1 \pm 1,0$ & $7,3 \pm 0,2$ & $8,9 \pm 0,3$ & $3,2 \pm 0,1$ \\
\hline \multirow{13}{*}{ 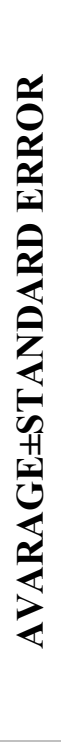 } & B & $210,1 \pm 1,4$ & $20,2 \pm 0,6$ & $6,0 \pm 0,2$ & $7,7 \pm 0,3$ & $3,3 \pm 0,2$ \\
\hline & $\mathrm{C}$ & $200,6 \pm 1,8$ & $20,3 \pm 0,7$ & $5,7 \pm 0,1$ & $6,2 \pm 0,1$ & $4,2 \pm 0,1$ \\
\hline & $\mathrm{D}$ & $182,0 \pm 1,7$ & $16,4 \pm 0,5$ & $5,3 \pm 0,1$ & $4,7 \pm 0,2$ & $4,8 \pm 0,3$ \\
\hline & E & $294,4 \pm 1,9$ & $33,8 \pm 0,7$ & $8,2 \pm 0,2$ & $9,4 \pm 0,3$ & $3,3 \pm 0,2$ \\
\hline & $\mathrm{F}$ & $306,5 \pm 1,8$ & $35,0 \pm 0,5$ & $11,0 \pm 0,1$ & $12,9 \pm 0,3$ & $3,2 \pm 0,1$ \\
\hline & G & $321,5 \pm 1,8$ & $36,1 \pm 0,6$ & $11,6 \pm 0,1$ & $12,1 \pm 0,3$ & $3,1 \pm 0,1$ \\
\hline & $\mathrm{H}$ & $243,0 \pm 3,1$ & $25,5 \pm 0,6$ & $7,5 \pm 0,2$ & $6,8 \pm 0,2$ & $3,2 \pm 0,1$ \\
\hline & K & $213,0 \pm 3,1$ & $23,4 \pm 0,4$ & $6,4 \pm 0,2$ & $6,0 \pm 0,2$ & $3,1 \pm 0,1$ \\
\hline & L & $197,0 \pm 1,7$ & $20,2 \pm 0,3$ & $5,7 \pm 0,1$ & $5,4 \pm 0,1$ & $3,1 \pm 0,1$ \\
\hline & M & $236,0 \pm 6,2$ & $25,9 \pm 0,7$ & $8,3 \pm 0,1$ & $9,5 \pm 0,2$ & $4,1 \pm 0,2$ \\
\hline & $\mathrm{N}$ & $206,6 \pm 1,8$ & $15,4 \pm 0,6$ & $5,9 \pm 0,1$ & $5,3 \pm 0,2$ & $3,6 \pm 0,2$ \\
\hline & $\mathrm{P}$ & $274,7 \pm 1,3$ & $26,2 \pm 0,3$ & $7,7 \pm 0,1$ & $7,4 \pm 0,2$ & $3,3 \pm 0,2$ \\
\hline & $\mathrm{R}$ & $220,0 \pm 2,2$ & $20,6 \pm 0,8$ & $6,1 \pm 0,6$ & $6,2 \pm 0,1$ & $4,1 \pm 0,2$ \\
\hline \multirow{15}{*}{$\stackrel{4}{2}$} & df & 139 & 139 & 139 & 139 & 139 \\
\hline & $\mathrm{F}$ & 278.5 & 114.2 & 204.9 & 105.3 & 11.0 \\
\hline & $P$ & $<0.001$ & $<0.001$ & $<0.001$ & $<0.001$ & $<0.001$ \\
\hline & \multirow{12}{*}{$\begin{array}{l}\text { Dunnet } \\
\text { test }\end{array}$} & $\mathrm{B}<0,05$ & B $<0,001$ & $A<0,05$ & $\mathrm{~B}<0,05$ & $\mathrm{C}<0.001$ \\
\hline & & $C<0.001$ & $C<0.001$ & $\mathrm{~B}<0.001$ & $C<0.001$ & $\mathrm{D}<0.001$ \\
\hline & & $\mathrm{D}<0.001$ & $\mathrm{D}<0.001$ & $C<0.001$ & $\mathrm{D}<0.001$ & $\mathrm{M}<0,05$ \\
\hline & & $\mathrm{E}<0.001$ & $\mathrm{E}<0.001$ & $\mathrm{D}<0.001$ & $\mathrm{~F}<0.001$ & $\mathrm{R}<0.05$ \\
\hline & & $\mathrm{F}<0.001$ & $F<0.001$ & $\mathrm{E}<0.001$ & $\mathrm{G}<0.001$ & \\
\hline & & $\mathrm{G}<0.001$ & $\mathrm{G}<0.001$ & $\mathrm{~F}<0.001$ & $\mathrm{~K}<0,001$ & \\
\hline & & $\mathrm{H}<0.001$ & $\mathrm{~L}<0.001$ & $\mathrm{~K}<0,05$ & $\mathrm{~L}<0.001$ & \\
\hline & & $\mathrm{K}<0,05$ & $\mathrm{~N}<0.001$ & $\mathrm{~L}<0.001$ & $\mathrm{~N}<0.001$ & \\
\hline & & $\mathrm{L}<0.001$ & $\mathrm{R}<0.001$ & $\mathrm{M}<0,05$ & $\mathrm{P}<0.001$ & \\
\hline & & $\mathrm{M}<0,05$ & & $\mathrm{~N}<0.001$ & $\mathrm{R}<0.001$ & \\
\hline & & $\mathrm{N}<0.001$ & & & & \\
\hline & & $P<0.001$ & & & & \\
\hline
\end{tabular}


When compared to control food, the minimum pupal protein content was obtained from the larvae feeding on the food (D) containing 5\% of TA. The highest pupal protein content was obtained from the larvae feeding on the food $(\mathrm{G})$ containing $5 \%$ of GA. Control food was lower than the foods (E, F and G) containing 1, 3 and 5\% of GA, but higher than the foods (B, C and D) containing 1, 3 and 5\% of TA. The pupal protein content of the larvae feeding on control food (except for $\mathrm{H}$ food) was more than the larvae feeding on $\mathrm{K}$ and $\mathrm{L}$ foods. It was found that of all the pupal protein content obtained from the larvae feeding on the foods containing double combinations, only the pupal protein content of the larvae feeding on $\mathrm{N}$ food was lower than the control food. The pupal protein content in $\mathrm{R}$ food was lower than the control food. However, it is significant that there was no statistical difference in the larvae feeding on $\mathrm{H}$ and $\mathrm{P}$ foods when compared to the control group.

\section{Pupal lipid content}

The pupal lipid content of the larvae feeding on the control food was statistically different from other groups. There was no statistical difference in the pupal lipid content of the larvae feeding on the food (M) containing TA+GA and the food (E) containing $1 \%$ of GA when compared to the control food. Compared to control food, as the secondary compounds which were added to the foods containing both tannic and $p$ coumaric acid increased, the pupal lipid content decreased. On the contrary, when the gallic acid concentration in foods containing gallic acid (except for the food containing $5 \%$ of GA) increased, the pupal lipid content also increased.

The minimum pupal lipid content was found in the larvae feeding on the food containing 5\% of TA. When compared to the control group, the group that had the maximum pupal and lipid content was obtained from the larvae feeding on the food (F) containing $3 \%$ of GA. It was found that lipid contents obtained from the pupae which fed on the foods containing 1, 3 and 5\% of GA (except for M food) were more than the other groups. The pupal lipid content in $\mathrm{R}$ food was more than the control food. When compared to the control food, there was not any statistical difference in the larvae feeding on $\mathrm{E}$ and $\mathrm{M}$ foods.

\section{Development time}

It was found that the development time of the larvae feeding on the control food was different from those feeding on C, D, M and R foods, but there was no statistical difference from the larvae feeding on the others foods. When tannic acid concentration increased, the development time was prolonged. On the contrary, when the gallic acid concentration in food containing gallic acid increased, the development time shortened. The shortest development time was observed in the larvae feeding on K, L and G foods. The longest development time was observed in the larvae feeding on D food.

\section{Discussion}

When three different concentrations of tannic acid, gallic acid and $p$-coumaric acid $(1,3$ and $5 \%)$ are taken into consideration, it can be seen that these three secondary compounds had different effects on the total food consumption of $H$. cunea larvae. When the secondary compounds in the foods (except for $\mathrm{H}$ food) containing both tannic and $p$-coumaric acid increased, the total food consumption of the larvae decreased. On 
the contrary, when the gallic acid concentration increased, the total food consumption of the larvae also increased.

Even though tannic acid, gallic acid and $p$-coumaric acid are three phenolic compounds, each of them had a different effect on $H$. cunea. Therefore, the result supports the statement in literature, which is, the chemical structure of phenolic compounds and the physiological roles vary with the phenolic in relation to the physicochemical environment (for example, $\mathrm{pH}$, redox potential, oxidase concentrations, oxidants and antioxidants) (Larson, 1995; Metadiewa et al., 1999; Sugihara et al., 1999; Galati et al., 2002; Sakihama et al., 2002; Hagerman et al., 2003). In this research, it was found that as the tannic acid concentration in the food increased, the total food consumption decreased. This result is opposite to the fact that the effects of the low levels of tannin on choosing foods and consumption amounts are hyperbole (Klocke and Chan, 1982).

Obtaining the minimum total food consumption from the larvae feeding on the food (D) containing 5\% of tannic acid resemble the results of the previous research in literature (Simpson and Raubenheimer, 2001; Hemming and Lindroth, 1995; Hemming and Lindroth, 2000). The reason for the decrease in total food consumption can result from the deterrent property of tannic acid on feeding.

The highest total food consumption (1,3 and 5\%) were the artificial foods (E, F and $\mathrm{G}$ foods) containing gallic acid. It is pointed out that free amino acids and trehalose concentration of basic blood glucose of the insects have an importance in feedback mechanism (Simpson and Raubenheimer, 1993; Simpson and Simpson, 1992; Friedman et al., 1991; Thompson and Redak, 2000). Therefore, the results may show that the gallic acid affected these two mechanisms.

The total food consumption of the larvae feeding on $\mathrm{M}$ food $(\mathrm{CF}+3 \%$ of $\mathrm{TA}+3 \%$ of GA) was much more than the control group. While the total food consumption obtained from the larvae feeding on $\mathrm{C}$ food was less than the control group, it is significant that two secondary compounds (tannic acid and gallic acid) in $\mathrm{M}$ food with synergistic effect were much more than the control group. Similarly, while the total food consumption of the larvae feeding on $\mathrm{P}$ food $(\mathrm{CF}+3 \%$ of $\mathrm{GA}+3 \%$ of $\mathrm{PCA})$ increased, it is significant that the total amount decreased in the larvae feeding on $\mathrm{K}$ food $(\mathrm{CF}+3 \%$ of $\mathrm{PCA})$ in comparison to the control group. The total food consumption in $\mathrm{N}$ food ( $\mathrm{CF}+3 \%$ of $\mathrm{TA}+3 \%$ of PCA) decreased when compared to the control group. The total food consumption in the larvae feeding on $\mathrm{C}$ and $\mathrm{K}$ food was less than the control group. It is an important result that there was no difference between the larvae feeding on $\mathrm{R}$ food and the control group. The results that were found in the larvae feeding on $\mathrm{M}, \mathrm{P}$ and $\mathrm{R}$ foods in particular may mean that the synergistic effect is different.

The pupal lipid contents in B, C and D foods decreased when compared to the control group. These foods all contained tannic acid (1, 3 and 5\% in order). Simpson and Raubenheimer (2001) have found in their study with Locusta migratoria that tannic acid has not prevented the carbohydrates in the foods from turning into fats in the body.

It is significant that the pupal lipid content of the larvae fed on $\mathrm{M}$ food was not different from the control group. However, while the pupal lipid content of the larvae feeding on $\mathrm{C}$ food decreased, the pupal lipid content of those feeding on $\mathrm{F}$ food increased. The similarity of the larvae feeding on $\mathrm{M}$ food that contains two secondary compounds shows the difference of the synergistic effects. On the other hand, the decrease in the pupal lipid content in the larvae feeding on $\mathrm{R}$ food that contains three secondary compounds and the difference from the results obtained from $\mathrm{M}$ food can 
show how triple synergistic effect can change. The foods containing the highest amount of pupal lipid content when compared to the control group were $\mathrm{F}(\mathrm{CF}+3 \%$ of $\mathrm{GA})$ and $\mathrm{G}(\mathrm{CF}+5 \%$ of GA) foods. There was no difference between the larvae feeding on $\mathrm{E}$ food ( $\mathrm{CF}+1 \%$ of GA) and the control group. This result may mean that gallic acid can show its effects in higher concentrations.

The lipids used during the adult period were derived from the lipids stored during the pre-adult phases (Giron and Casas, 2003). When the concentration increased in the larvae feeding on the foods that contained only tannic acid (1,3 and 5\%) and $p$-coumaric acid (1, 3 and 5\%) concentration, the decrease in the lipid content could be a disadvantage for $H$. cunea and the highest lipid content of the larvae feeding on the foods with gallic acid could be an advantage.

The two highest amounts of pupal protein content ( $\mathrm{F}$ and $\mathrm{G}$ foods) when compared to the control group were found in the larvae feeding on the foods that contained gallic acid. While there was no difference between the control group and the larvae feeding on $\mathrm{P}$ food (synergy), it is significant that the lipid content in the larvae feeding on $\mathrm{F}$ food was high. The low amount of pupal protein content in triple combinations ( $\mathrm{R}$ food) when compared to the control group may mean that the negative effect of tannic acid and $p$-coumaric acid in the food transcended the positive effect of gallic acid. The stored proteins carried from the larval period to the adult period can play an important role especially due to the limited nitrogen consumption of adult herbivore insects (Hahn, 2005). Therefore, the gallic acid in the foods can be an advantage in stored protein. In this study, when tannic acid and $p$-coumaric acid concentrations in the foods (except for $\mathrm{H}$ food) increased, pupal protein content decreased. However, it was pointed out that the protein content of $L$. migratoria was higher than those feeding on foods without tannic acid (Simpson and Raubenheimer, 2001). In the single, double and triple combinations of tannic acid (except for TA+GA combination), all the groups have a low amount of pupal protein content. In this study, the reason for the pupal protein content to be low in the food groups containing tannic acid when compared to the other secondary compounds can result from the tannic acid having a more negative effect.

Simpson and Raubenheimer (2001) have pointed out when the amount of tannic acid increases in the grasshoppers feeding on foods with tannic acid, the weight decreases in $L$. migratoria. Similarly in this study, when the tannic acid concentration increased (except for $\mathrm{C}$ food), the pupal weight decreased. This result is similar to the statement that both in insects and vertebrates, the negative effects of tannins can be related to the high tannin concentration (Aerts et al., 1999). The lowest pupal weight was found in the larvae feeding on $\mathrm{N}(\mathrm{CF}+3 \%$ of $\mathrm{TA}+3 \%$ of PCA) food. Even though there was no difference between the larvae feeding on $\mathrm{K}$ food $(\mathrm{CF}+3 \%$ of $\mathrm{PCA})$ when compared to the control group, the lowest amount in the larvae feeding on $\mathrm{N}$ food can show the synergistic effect.

The previous research pointed out that the differences in the secondary compounds content change the food choice and performance of Malacosoma disstria larvae in a definite way (Hemming and Lindroth, 1995; Hemming and Lindroth, 2000). The highest amounts of pupal weight were found in the larvae feeding on E, F and G foods. The low weight of the pupae can affect the fecundity of the adult females (Honek, 1993). The higher amount of weight of the larvae feeding on foods containing gallic acid (E, F and $\mathrm{G}$ foods) can affect fecundity positively.

The longest development time was observed in the larvae feeding on $\mathrm{C}$ and $\mathrm{D}$ foods. Simpson and Raubenheimer (2001) have found that the larval periods extend when tannic acid is added to the food in L. migratoria. The extension of development time, the chance 
of facing the natural enemies during feeding or searching for food (Bernays, 1997) or the increase of predator/parasitism risk with a longer development and feeding time (Moran and Hamilton, 1980; Loader and Damman, 1991; Benrey and Denno, 1997) are also available for this species. One of the significant results of this study is that the development time of the larvae fed on $\mathrm{M}$ and $\mathrm{R}$ foods also lengthened out. It can be said that tannic acid in both foods had a stronger effect on the synergistic effect than gallic acid and $p$-coumaric acid. Ehrlich and Raven (1964) expressed that during the coevolution process, following the spread and speciation of insects, new defense substances emerge on the parts of plants and then defenses against insects evolve. Even though some of the herbivore insects are adapted to newly produced defensive compounds sooner or later (Bernays, 1998); in this study the negative effect of tannic acid on the development time of $H$. cunea larvae is obvious.

\section{Conclusions}

It can be said that $H$. cunea larvae, a polyphagous insect, have a great ecological tolerance to feeding and secondary compounds. Having a great ecological tolerance to secondary compounds may mean that it is hard to struggle with $H$. cunea during population explosion.

In this research, the reaction of $H$. cunea to different secondary compounds was determined and it was observed that the larvae were resistant to concentrations of the secondary compounds and could reach the pupal period. Even though it is believed that plant phenolics play an important role in chemical defense against herbivores, some specific physiological effects of them can be changed on insects (Harborne, 1991; Appel, 1993). It can be said that $H$. cunea larvae are physiologically resistant to secondary compounds. Moreover, the results obtained from the larvae fed on double and triple combinations of secondary compounds used in this research show that the synergistic effect is different. Further research with other species will make the significance of the synergistic effect become clearer.

Acknowledgements. We would like to thank the support of Ondokuz Mayis University and our colleagues in carrying out this study.

\section{REFERENCES}

[1] Aerts, R.J., Barry, T.N., McNabb, W.C. (1999): Polyphenols and agriculture: beneficial effects of proanthocyanidins in forages. - Agriculture Ecosystem and Environment 75: 112.

[2] Appel, H. (1993): Phenolics in ecological interactions: The importance of oxidation. Journal of Chemical Ecology 19: 1521-1552.

[3] Baas, W.J. (1989): Secondary plant compounds, their ecological significance and consequences for the carbon budget. - In: Lambers, H., Cambridge, M.L., Konings, H., Pons, T.L. (ed.) Causes and consequences of variation in growth rate and productivity of higher plants, Introduction of the carbon/nutrient cycle theory, Netherlands, 313-340.

[4] Benrey, B., Denno, R.F. (1997): The slow-growth-high-mortality hypothesis: a test using the cabbage butterfly. - Ecology 78: 987-999.

[5] Berenbaum, M. (1982): Coumarins and Caterpillars: A Case for Coevolution. - Evolution 37: 163-179. 
[6] Bernays, E.A., Driver, G.C., Bilgener, M. (1989): Herbivores and plant tannins. Advances in Ecological Research 19: 263-302.

[7] Bernays, E.A. (1997): Feeding by lepidopteran larvae is dangerous. - Ecological Entomology 22: 121-123.

[8] Bernays, E.A. (1998): Evolution of feeding behaviour in insect herbivores. - Bioscience 48: 35-45.

[9] Chou, C.H., Kuo, Y.L. (1986): Allelopathic research of subtropical vegetation in Taiwan. Allelopathic exclusion of understorey by Leucaena leucophylla (Lam) de Wit. - Journal of Chemical Ecology 12: 1431-1448.

[10] Dicke, M., Sabelis, M.W. (1989): Does it pay plants to advertise for bodyguards? - In: Lambers, H., Konings, H., Cambridge, M.L., Pons, Th.L. (ed.) Consequences of Variation in Growth Rate and Productivity of Higher Plants, Towards a cost-benefit analysis of induced synomone production, Netherlands, 341-358.

[11] Ehrlich, P.R., Raven, P.H. (1964): Butterflies and plants: a study in co-evolution. Evolution 18: 586-608.

[12] Fraenkel, G.S. (1959): The raison d'être of secondary plant substances. The odd chemicals arose as a means of protecting plants from insects and now guide insects to food. - Science 129: 1466-1470.

[13] Friedman, S., Waldbauer, G.P., Eertmoed, J.E., Naeem, M., Ghent, A.W. (1991): Blood trehalose levels have a role in the control of dietary self-selection by Heliothis zea larvae. - Insect Physiology 37: 919-928.

[14] Galati, G., Sabzevari, O., Wilson, J.X., O'brien, P.J. (2002): Prooxidant activity and cellular effects of the phenoxyl radicals of foodary flavonoids and other polyphenolics. Toxicology 177: 91-104.

[15] Giftson, J.S., Jayanthi, S., Nalini, N. (2009): Chemopreventive efficacy of gallic acid, an antioxidant and anticarcinogenic polyphenol, against 1, 2-dimethyl hydrazine induced rat colon carcinogenesis. - Investigation New Drugs 28: 251-259.

[16] Giron, D., Casas, J. (2003): Lipogenesis in adult Parasitic Wasp. - Journal of Insect Physiology 49: 141-147.

[17] Hagerman, A.E., Dean, R.T., Davies, M.J. (2003): Radical chemistry of epigallocatechin gallate and its relevance to protein damage. - Archives of Biochemistry and Biophysics 414: 115-120.

[18] Hahn, D.A. (2005): Larval nutrition affects lipid storage and growth, but not protein or carbohydrate storage in newly eclosed adults of the grasshopper Schistocerca americana. - Journal of Insect Physiology 51: 1210-1219.

[19] Harborne, J.B. (1977): Introduction to Ecological Biochemistry. - Academic Press, London, 70-95.

[20] Harborne, J.B. (1991): Flavonoid Pigments. - In: Rosenthal G.A., Berenbaum M.B. (ed.) Herbivores: Their Interactions with Secondary Plant Metabolites, Vol I., Academic Press, New York, 389-429.

[21] Hemming, J.D.C., Lindroth, R.L. (1995): Intraspecific variation in aspen phytochemistryeffects on performance of gypsy moths and forest tent caterpillars. - Oecologia 103: 7988 .

[22] Hemming, J.D.C., Lindroth, R.L. (2000): Effects of phenolic glycosides and protein on gypsy moth (Lepidoptera: Lymantriidae) and forest tent caterpillar (Lepidoptera: Lasiocampidae) performance and detoxication activities. - Environmental Entomology 29: $1108-1115$.

[23] Henriksson, J., Haukioja, E., Ossipov, V., Ossipova, S., Sillanpa, A.S., Kapari, L., Pihlaja, K. (2003): Effects of host shading on consumption and growth of the geometrid Epirrita autumnata: interactive roles of water, primary and secondary compounds. Oikos 103: 3-16.

[24] Honek, A. (1993): Intraspecific variation in body size and fecundity in insects-a general relationship. - Oikos 66: 483-492. 
[25] Kang, M.S., Oh, J.S., Kang, I.C., Hong, S.J., Choi, C.H. (2008): Inhibitory effect of methyl gallate and gallic acid on oral bacteria. - Journal of Microbiology 46: 744-750.

[26] Kim, S.H., Jun, C.D., Suk, K., Choi, B.J., Lim, H., Park, S., Lee, S.H., Shin, H.Y., Kim, D.K., Shin, T.Y. (2006): Gallic acid inhibits histamine release and pro-inflammatory cytokine production in mast cells. - Toxicological Sciences 91: 123-131.

[27] Klocke, J.A., Chan, B.G. (1982): Effects of cotton condensed tannin on feeding and digestion in the cotton pest, Heliothis zea. - Journal of Insect Physiology 28: 911-916.

[28] Larson, R.A. (1995): Antioxidant mechanisms of secondary natural products. - In: Ahmad, S. (ed.) Oxidant-induced Stress and Antioxidant Defenses in Biology, Chapman and Hall, New York, 210-237.

[29] Lee, K.P., Behmer, S.T., Simpson, S.J., Raubenheimer, D. (2002): A geometric analysis of nutrient regulation in the generalist caterpillar Spodoptera littoralis (Boisduval). Journal of Insect Physiology 48: 655-665.

[30] Lee, K.P., Raubenheimer, D., Simpson, S.J. (2004): The effects of nutritional imbalance on compensatory feeding for cellulose-mediated foodary dilution in a generalist caterpillar. - Physiological Entomology 29: 108-117.

[31] Loader, C., Damman, H. (1991): Nitrogen content of food plants and vulnerability of Pieris rapae to natural enemies. - Ecology 72: 1586-1590.

[32] Metadiewa, D., Jaiswal, A.K., Cenas, N., Dickancaite, E., Segura-Auilar, J. (1999): Quercetin may act as a cytotoxic prooxidant after its metabolic activation to semiquinone and quinoidal product. - Free Radical Biology and Medicine 26: 107-116.

[33] Moran, N., Hamilton, W.D. (1980): Low nutritive quality as defense against herbivores. Journal of Theoretical Biology 86: 247-254.

[34] Peters, D.J., Constabel, C.P. (2002): Molecular analysis of herbivore-induced condensed tannin synthesis: cloning and expression of dihydroflavonol reductase from trembling aspen (Populus tremuloides). - The Plant Journal 32: 701-712.

[35] Sakihama, Y., Cohen, M.F., Grace, S.C., Yamasaki, H. (2002): Plant phenolic antioxidant and prooxidant activities: phenolics-induced oxidative damage mediated by metals in plants. - Toxicology 177: 67-80.

[36] Simpson, S.J., Raubenheimer, D. (1993): The central role of the haemolymph in the regulation of nutrient intake in insects. - Physiological Entomology 18: 395-403.

[37] Simpson, S.J., Raubenheimer, D. (2001): The geometric analysis of nutrientallelochemical interactions: a case study using locusts. - Ecology 82: 422-439.

[38] Simpson, S.J., Simpson, C.L. (1992): Mechanism controlling modulation by amino acids of gustatory responsiveness in the locust. - Journal of Experimental Biology 168: 269287.

[39] Strack, D. (1997): Phenolic metabolism. - In: Dey, P.M., Harborne, J.B. (ed.) Plant biochemistry, Academic Press, New York, 387-416.

[40] Sugihara, N., Arakawa, T., Ohnishi, M., Furuno, K. (1999): Anti- and pro-oxidative effects of flavonoids on metal-induced lipid hydroperoxide-dependent lipid peroxidation in cultured hepatocytes loaded with a-linolenic acid. - Free Radical Biology and Medicine 27: 1313-1323.

[41] Telang, A., Booton, V., Chapman, R.F., Wheeler, D.E. (2001): How female caterpillars accumulate their nutrient reserves. - Journal of Insect Physiology 47: 1055-1064.

[42] Thompson, S.N., Redak, R.A. (2000): Interactions of dietary protein and carbohydrate determine blood sugar level and regulate nutrient selection in the insect Manduca sexta $\mathrm{L}$. - Biochimica et Biophysica Acta-General Subjects 1523: 91-102.

[43] Torres, J., Rosazza, J.P.N. (2001): Microbial transformations of $p$-coumaric acid by Bacillus megaterium and Curvularia lunata. - Journal of Natural Products 64(11): 14081414.

[44] Yamamoto, R.T. (1969): Mass rearing of tobacco hornworm. II. Larval rearing and pupation. - Journal of Economic Entomology 62: 1427-1431. 